\title{
Quantitative Retrieval of Soil Moisture Content in the Upper Reaches of the Minjiang River
}

\author{
Xie Bing, Yang Wu-nian*, Dai Xiao-ai, Wang Yu-lan, Yang Xin \\ Key Laboratory of Geoscience Spatial Information Technology of Land and Resources, \\ Chengdu University of Technology, Chengdu, China
}

Received: 20 August 2017

Accepted: 16 October 2017

\begin{abstract}
This paper analyzes the correlation between soil moisture data and different spectral data transformation, and it reveals that the correlation coefficient of soil moisture is highest near $584 \mathrm{~nm}$, $711 \mathrm{~nm}, 1,055 \mathrm{~nm}, 1,420 \mathrm{~nm}, 1,635 \mathrm{~nm}, 2,176 \mathrm{~nm}$, and 2,257 nm. The highest correlation coefficient can be up to 0.83206 . Multiple regression analysis can be done to understand the correlation between the two, find out the reflectance values at the above fixed spectrum through a bilinear correlation, and quantitatively invert soil moisture in the study area, shedding new light on soil moisture in this large area.
\end{abstract}

Keywords: soil moisture content, remote sensing retrieval, sensitive spectral band

\section{Introduction}

Soil moisture content plays an important role in vegetation growth, which in turn determines ecological balance [1-4]. A strong understanding of soil moisture content can help assess vegetation growth and water deficit status. Whether crops need watering or if there are drought conditions can be determined by measuring soil moisture content [5-9].

Traditionally, equipment was used to measure soil moisture content at the sampling points; however, this method has certain disadvantages, like slower speed, limited sampling points, and extensive area under measurement, and monitoring results hardly reflect general soil moisture content status [10-14]. It is feasible to obtain soil moisture content from spectral reflectance, considering differences in spectral reflectance as a result of differences in soil moisture content, and mineral and

*e-mail: ywn@cdut.edu.cn organic matter content. Since remote sensing images cover the entire study area, soil moisture content for the entire region can be monitored, instead of for just representative points [15-19]. That is to say, remote sensing technology combined with modeling offers a better solution [20-23].

It should be noted that the choice of mathematical modeling is highly important given variations in soil content in each study region. Spectral measurement and soil moisture content measurement were first performed in this study using a spectrometer. The relationship between spectral bands and soil moisture content was later established through multiple linear regression techniques.

ASD FieldSpec Pro FR was used for spectral measurement of different soil types in the Maoergai Region, and spectral reflectance curves for each soil type were obtained. Similarly, soil samples were collected from different areas and dried to a constant weight. The spectral bands sensitive to soil moisture content were then identified. The reflectance of the most sensitive band having the largest coefficient of 
determination was chosen using multiple regression analysis. A model was then built between reflectance of this sensitive band and soil moisture content. Finally, soil moisture content in the study area was retrieved using remote sensing images. This research sheds new light on drought monitoring over large areas and development of precision agriculture.

\section{Material and Methods}

\section{An Overview of the Study Area}

The Minjiang River is a tributary of the Yangtze River, and is located in the middle of Sichuan Province. Flowing at an altitude of 3,000-4,000 m, the Minjiang has rich vegetation and animal resources. Its full length is $337 \mathrm{~km}$ and the area of the drainage basin is $22,000 \mathrm{~km}^{2}$. The annual average temperature is $5-6^{\circ} \mathrm{C}$, with high precipitation throughout the year. The upper reaches of the Minjiang include counties such as Wenchuan, Dujiangyan, Maoxian, Lixian, and Songpan, where water conservation facilities are more developed. Since the ecosystem of the upper reaches directly influences that of the lower reaches of Chengdu Plain and the Yangtze River, the upper reaches of the Minjiang were chosen as the representative region. The soil moisture content in this region was then gauged.

In the extensive upper reaches of the Minjiang, the focus was on the Maoergai Region, which covers an area of $0.18 \mathrm{~km}^{2}$ and lies between Songpan and Heishui counties, as shown in Fig. 1. This region has diverse soil types featuring high soil moisture content.

\section{Soil Sample Collection and Processing}

Sampling sites for each soil type were selected. Surface humus was removed during collection, and collection depth was $0-10 \mathrm{~cm}$. The soil samples were weighed, placed into sealed bags, and numbered. The geographical position of the sampling point was determined with a hand-held GPS receiver, and the sampling point was numbered using its geographical position.

The soil weight was recorded as al (exact to $0.0001 \mathrm{~g}$, including the aluminum case's weight). At the laboratory, the soil sample was transferred to another dry aluminum case (with the same weight as the original case) and placed in an oven with temperature adjusted to $120^{\circ} \mathrm{C}$. The soil was weighed again after drying for 6-8 $\mathrm{h}$ with weight recorded as a2 (including the aluminum case). The soil moisture content was calculated using the formula:

$$
w=\frac{(a 1-a 2)}{a 1} \times 100 \%
$$

\section{Spectral Data Acquisition and Processing}

ASD FieldSpec Pro FR (measuring range 350-2, $500 \mathrm{~nm}$ ) was used to collect spectral data of the soil. As the spectrometer was exposed to environmental factors, the soil's measured reflectance may contain some deviations. Therefore, respective values were corrected using a standard whiteboard. The reflectance was measured thrice and values recorded three times

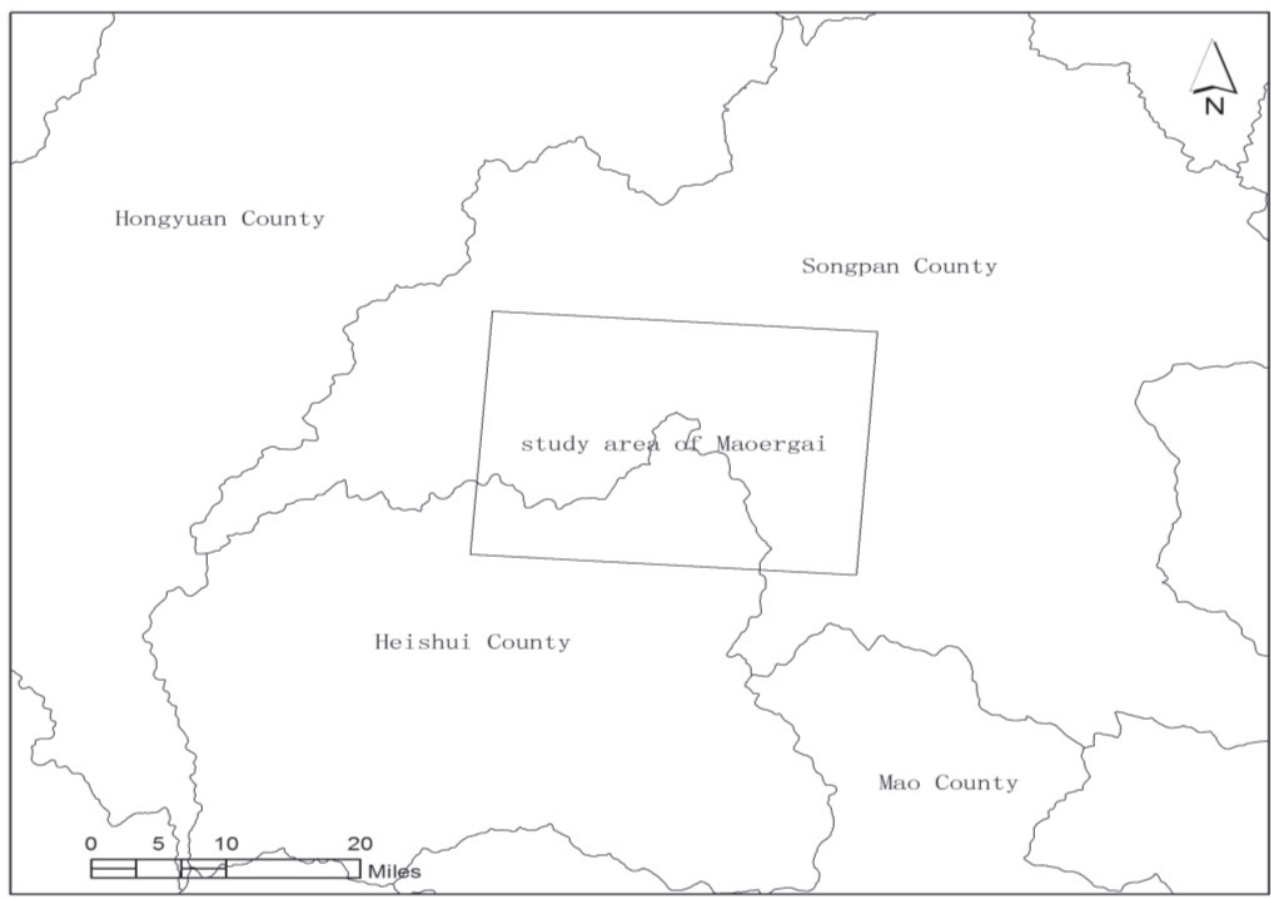

Fig. 1. Sketch map of study area. 


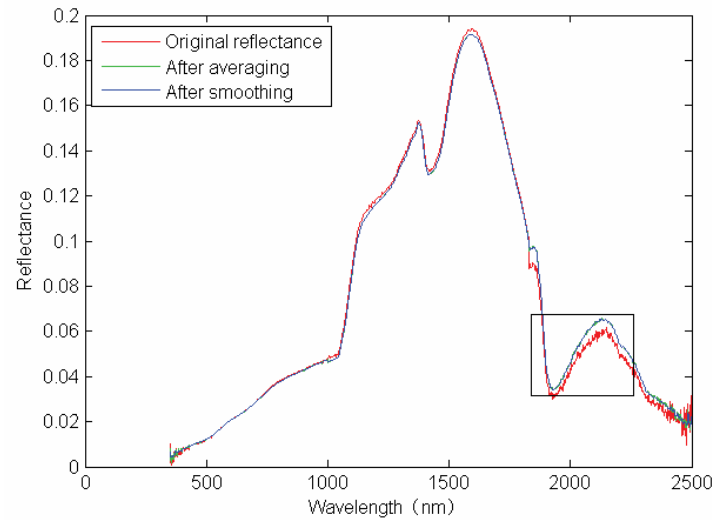

Fig. 2. Spectral reflectance curves after smoothing.

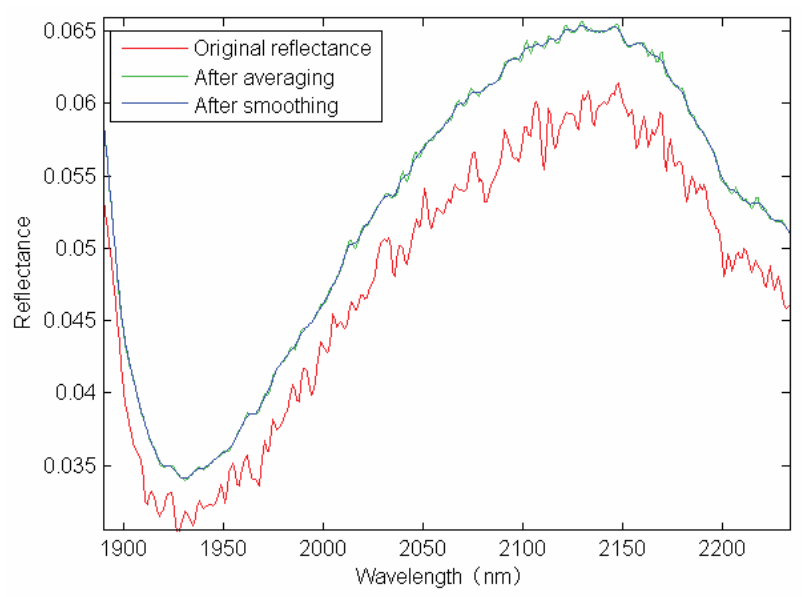

Fig. 3. Effect diagram of the rectangle in the above figure.

each using a spectrometer for each measurement. Hence, 9 measurements were obtained for each sampling site. The reflectance of the soil was calculated using the formula:

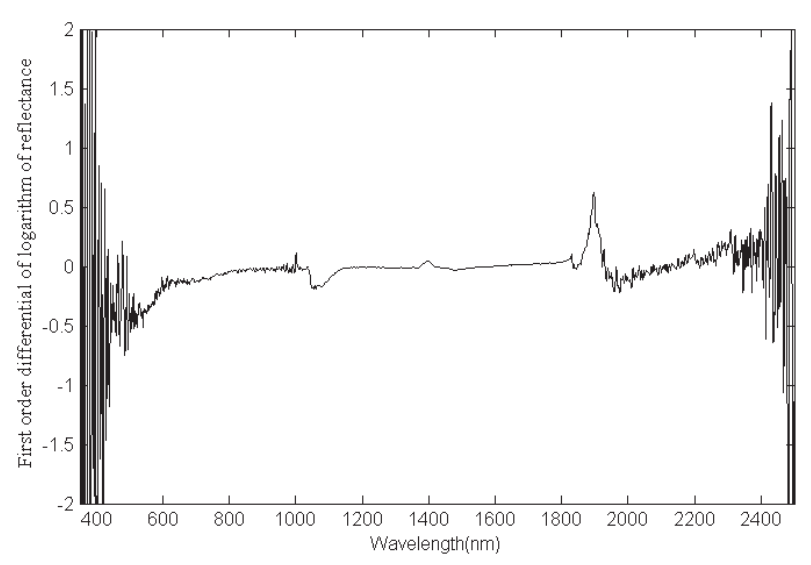

Fig. 4. First-order differential of logarithm of reflectance for A001 sample.

$$
\rho_{i}=\frac{I_{i}}{I_{i}^{0}} \times \rho_{i}^{0} \quad i=1,2 \ldots n
$$

...where $\rho_{i}$ is soil reflectance at $i ; I_{i}$ and $I_{i}^{0}$ are radiation intensity of soil and whiteboard, at $i$, respectively; $\rho_{i}^{0}$ is whiteboard reflectance; and $n$ is the number of sampling points, which is 9 in this study.

Denoising was then performed on the spectral data collected in the field. The raw data was corrected using ViewSpec Pro software; the reflectance was subsequently averaged (of 9 measurements) after a smoothing process (by moving the averaging method under the MATLAB environment).

The spectral reflectance curves after denoising and smoothing are displayed in Figs 2 and 3, and can be compared to those before smoothing. It can be seen that the curves are better after smoothing.

\section{Construction of Soil Parameter Prediction Model}

The reflectance curves for different bands seem to coincide. To choose the most sensitive band, mathematical conversion was performed for the soil reflectance data. The logarithm of reflectance, reciprocal of reflectance, first-order differential of reciprocal of reflectance (Fig. 4), first-order differential of reflectance, and first-order differential of logarithm of reflectance were calculated. By doing so, the characteristic points on the spectral curves were obtained so as to determine the most sensitive band, and the non-linear influence was removed.

The noise was especially large in the range 350-450 nm and 2,451-2,500 nm using ASD FieldSpec Pro FR. Thus reflectance data within these two ranges were eliminated [10]. Correlation analysis was performed between each converted form of reflectance and soil moisture content. The coefficient of determination was calculated under MATLAB environment, as shown in Table 1.

After selecting the most sensitive band, the relationship between soil moisture content and reflectance of this sensitive band was modeled, as shown in Table 2. The largest coefficient of determination was found with reciprocal of reflectance. For the sake of comparison, soil moisture content was retrieved using reciprocal of reflectance and first-order differential of reflectance, respectively.

\section{Results and Discussion}

\section{Pretreatment of TM Images}

To eliminate errors related to environmental factors (atmospheric reflection and refraction) and system-based sensor errors, the following procedures were performed: remote sensing images were corrected, including 
Table 1. Converted forms of reflectance and corresponding sensitive bands.

\begin{tabular}{|c|c|c|}
\hline Converted form of reflectance & Sensitive band (nm) & Coefficient of determination \\
\hline Reflectance & $584 \quad 1085 \quad 1932$ & $\begin{array}{llll}0.39009 & 0.22248 & 0.38427\end{array}$ \\
\hline Reciprocal of reflectance & $\begin{array}{llll}584 & 1055 & 1271 & 1831\end{array}$ & $\begin{array}{lllll}0.32474 & 0.29019 & 0.28969 & 0.26055\end{array}$ \\
\hline Logarithm of reflectance & $\begin{array}{lll}584 & 1070 & 1930\end{array}$ & $0.40500 \quad 0.28236 \quad 0.22504$ \\
\hline First-order differential of reflectance & $\begin{array}{lllll}856 & 1351 & 1611 & 2162 & 2256\end{array}$ & $\begin{array}{llllll}0.77429 & 0.6936 & 0.53579 & 0.68900 & 0.68674\end{array}$ \\
\hline $\begin{array}{l}\text { First-order differential of reciprocal } \\
\text { of reflectance }\end{array}$ & $\begin{array}{lllll}673 & 1419 & 1635 & 2176 & 2257\end{array}$ & $\begin{array}{llllll}0.74287 & 0.57351 & 0.57138 & 0.61766 & 0.74116\end{array}$ \\
\hline $\begin{array}{c}\text { First-order differential of logarithm } \\
\text { of reflectance }\end{array}$ & $\begin{array}{lllll}711 & 1423 & 1596 & 2176 & 2257\end{array}$ & $\begin{array}{llllll}0.83206 & 0.85108 & 0.71136 & 0.80185 & 0.75118\end{array}$ \\
\hline
\end{tabular}

Table 2. Mathematical model between soil moisture content and reflectance of the sensitive band.

\begin{tabular}{|c|c|c|}
\hline Converted form of reflectance & $\begin{array}{c}\text { Mathematical model between soil moisture content } \\
\text { and each form of reflectance }\end{array}$ & $\begin{array}{c}\text { Coefficient } \\
\text { of determination }\end{array}$ \\
\hline Reflectance & $\mathrm{Y}=0.2869+3.423 \mathrm{x}_{1085}+(-11.342) \mathrm{x}_{1932}$ & $\mathrm{R}^{2}=0.545177$ \\
\hline Reciprocal of reflectance & $\mathrm{Y}=0.2346+0.0050 \mathrm{x}_{584}-0.0305 \mathrm{x}_{1055}+0.0199 \mathrm{x}_{1831}$ & $\mathrm{R}^{2}=0.866349$ \\
\hline Logarithm of reflectance & $\mathrm{Y}=-0.05354-0.09811 \mathrm{x}_{584+}-24645 \mathrm{x}_{1070}-0.16604 \mathrm{x}_{1930}$ & $\mathrm{R}^{2}=0.678145$ \\
\hline First-order differential of reflectance & $\mathrm{Y}=0.20367+1249.3914 \mathrm{x}_{2162}-1367.6815 \mathrm{x}_{2256}$ & $\mathrm{R}^{2}=0.708648$ \\
\hline First-order differential of reciprocal of reflectance & $\mathrm{Y}=0.20605-0.78472 \mathrm{x}_{673}-1.29663 \mathrm{x}_{2257}$ & $\mathrm{R}^{2}=0.807532$ \\
\hline First-order differential of logarithm of reflectance & $\mathrm{Y}=0.95137+32.96367 \mathrm{x}_{711}-0.78826 \mathrm{x}_{1423}-145.07185 \mathrm{x}_{1596}$ & $\mathrm{R}^{2}=0.803321$ \\
\hline
\end{tabular}

radiation calibration, FLAASH atmospheric correction, image mosaics, and TM images of the study area were clipped (see Fig. 5).

\section{Obtaining Sensitive Bands on TM Images}

For TM images with fewer bands, spectral reflectance at a longer wavelength needs to be retrieved accurately. In this case, spectral reflectance was obtained by fitting on TM images. This method had higher

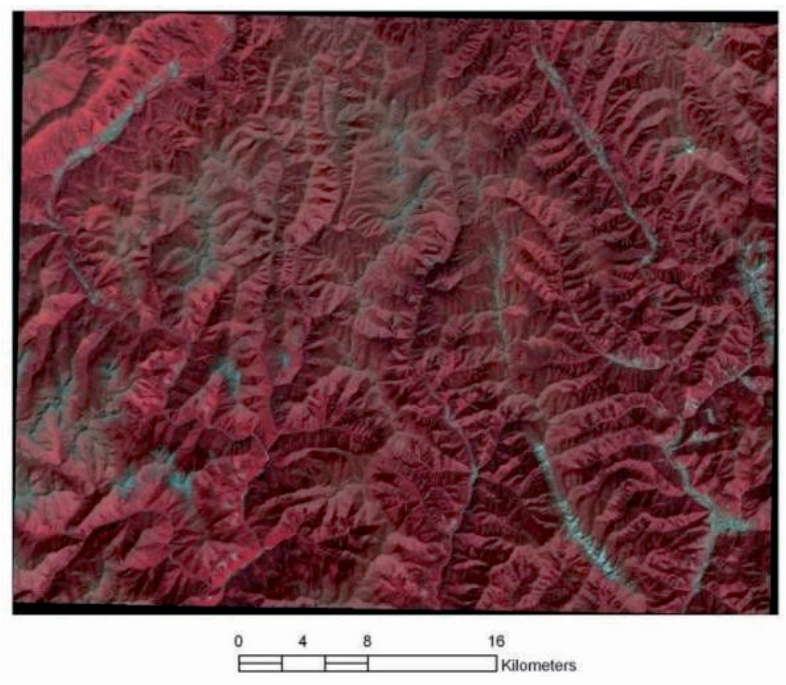

Fig. 5. Pretreatment of TM images of the study area. accuracy compared to using reflectance of an adjacent band as the reflectance, at a specific wavelength.

Before fitting, reflectance of each band on TM images was determined as reflectance at the central wavelength of each band. Then reflectance at a specific wavelength was fitted, based on reflectance at the central wavelength of the adjacent band.

For instance, spectral reflectance and corresponding reflectance at the central wavelength for a certain pixel in the fourth and the fifth bands were plotted on $y$-axis and $x$-axis, respectively, as shown in Fig. 6. The

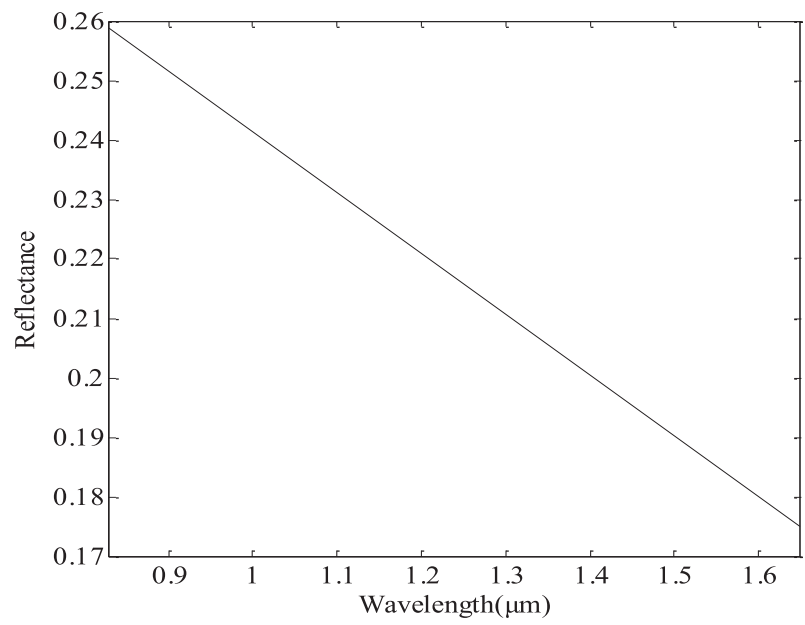

Fig. 6. Curve before fitting. 


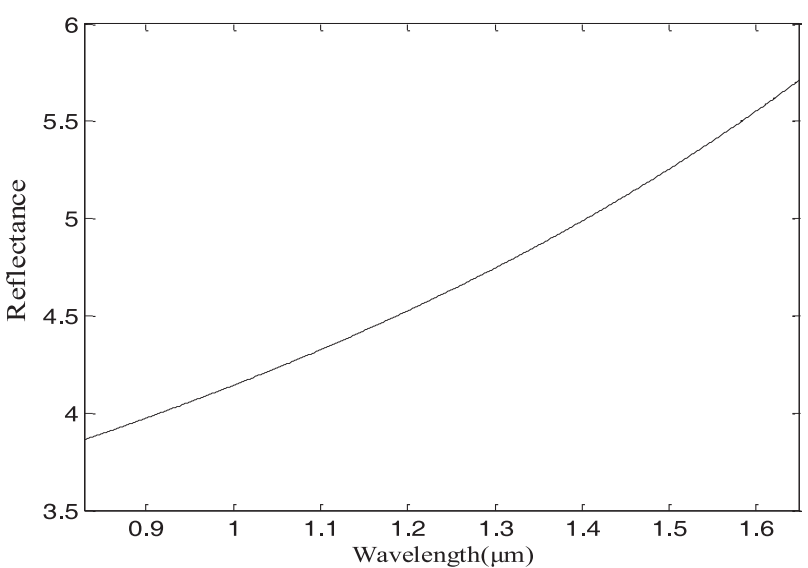

Fig. 7. Curve after fitting.

curve is shown in Fig. 7 after fitting and logarithmic transformation.

\section{Quantitative Retrieval of Soil Moisture Content}

Under MATLAB environment [13] the image data was stored in ASCII format and subjected to mathematical processing. The images were then restored using remote sensing image processing software. Since the data in ASCII format was huge, all the data could not be read at a time; hence, the files in ASCII format were segmented. For instance, each TM images' band had 1,996,446 double values, which means a large data load is required for fitting. After calculation, the files in ASCII format were segmented into 6 parts to be processed separately, as shown in Table 3.

Classification maps based on soil moisture content retrieved from first-order differential of the reciprocal of reflectance are displayed in Fig. 8.

It can be seen that the entire study area had high soil moisture content. Statistics derived from pixel values revealed that soil moisture content using the two methods differed slightly. Average soil moisture content retrieved from reciprocal of reflectance was $44.92 \%$, while that retrieved from first-order differential of the reciprocal of reflectance was $66.59 \%$. In earlier soil sample analysis, soil moisture content was generally

Table 3. Initial values for each part.

\begin{tabular}{|c|c|c|c|}
\hline $\begin{array}{c}\text { Initial value } \\
\text { for the } \\
\text { second band }\end{array}$ & $\begin{array}{c}\text { End value for } \\
\text { the second } \\
\text { band }\end{array}$ & $\begin{array}{c}\text { Initial value } \\
\text { for the third } \\
\text { band }\end{array}$ & $\begin{array}{c}\text { End value } \\
\text { for the third } \\
\text { band }\end{array}$ \\
\hline 1 & 332742 & 1 & 332742 \\
\hline 332743 & 665484 & 332743 & 665484 \\
\hline 665485 & 998226 & 665485 & 998226 \\
\hline 998227 & 1330968 & 998227 & 1330968 \\
\hline 1330969 & 1663710 & 1330969 & 1663710 \\
\hline 1663711 & 1996446 & 1663711 & 1996446 \\
\hline
\end{tabular}

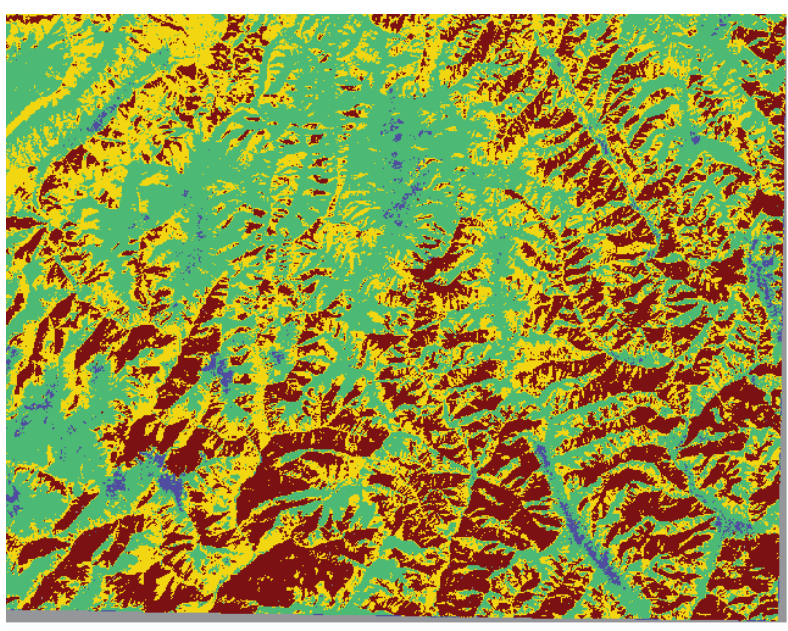

Legend of soil moisture content $0-.120000000$

$.120000000-.240000000$ $.240000000-.36000000$ $.360000000-.48058845$ $.480588450-.600000024$

Fig. 8. Classification map based on soil moisture content retrieved from first-order differential of reciprocal of reflectance.

around $40 \%$. Soil moisture content retrieved from reciprocal of reflectance was more accurate than that retrieved from first-order differential of the reciprocal of reflectance. This coincided with the fact that coefficient of determination was higher when reciprocal of reflectance was used than when first-order differential of the reciprocal of reflectance was used.

\section{Calculation of Soil Moisture Content in the Study Area}

\section{Total Soil Moisture Content was Calculated for the Study Area}

Assuming that soil density was $2.65 \mathrm{~g} / \mathrm{cm}^{3}$, soil thickness was $0.1 \mathrm{~m}$ and pixel size of TM image was $30 \mathrm{~m}$, based on soil moisture content results (Fig. 8), then

$$
m=\sum \rho \cdot s \cdot h \cdot w
$$

...where $\mathrm{m}$ is total moisture content in surface soil, $\rho$ is soil density, $s$ is area of a single pixel, $h$ is soil thickness and equal to $0.1 \mathrm{~m}$, and $w$ is soil moisture content of each pixel.

Moisture content of surface soil in the study area was then calculated as $2.14 \times 108 \mathrm{t}$.

\section{Conclusions}

In this paper the relationship between soil moisture and spectrum is analyzed using mathematical correlation. Soil moisture and soil spectral rate in 
the study area was measured in the field, leading to the conclusion that correlation coefficients of soil moisture were relatively larger at $584 \mathrm{~nm}, 711 \mathrm{~nm}$, $1,055 \mathrm{~nm}, 1,420 \mathrm{~nm}, 1,635 \mathrm{~nm}, 2,176 \mathrm{~nm}$, and 2,257 nm, respectively. Finally, the most appropriate regression model was selected by inverting the soil moisture through remote sensing images of the area under study:

$$
\begin{aligned}
& Y=0.2346+0.0050 x_{584}-0.0305 x_{1055}+0.0199 x_{1831} \\
& Y=0.20605-0.78472 x_{673}-1.29663 x_{2257}
\end{aligned}
$$

Surface soil moisture is $2.14 \times 108 \mathrm{t}$, calculated based on Formula (3) and the TM image pixel. Thus, this provides a reference for studying soil moisture and environmental evaluation of larger areas using remote sensing data.

\section{Acknowledgements}

Our project was supported by the National Natural Science Foundation of China (grant Nos. 41071265 and 41372340)

\section{References}

1. CHAMPAGNE C., MCNAIRN H., BERG A.A. Monitoring agricultural soil moisture extremes in Canada using passive microwave remote sensing. Remote Sensing of Environment, 115, 2434, 2011.

2. DANIEL A.S., JOHN A.G. Estimation of vegetation water content and photosynthetic tissue area from spectral reflectance: a comparison of indices based on liquid water and chlorophyll absorption features. Remote Sensing of Environment, 84, 526, 2003.

3. JEU R.A.M., WAGNER W., HOLMES T.R.H., DOLMAN A.J., van de GIESEN N.C., FRIESEN J. Global soil moisture patterns observed by space borne microwave radiometers and scatterometers. Surveys in Geophysics, 29, 399, 2008.

4. FLORES A.N., IVANOV V.Y., ENTEKHABI D., BRAS R.L. Impact of hillslope-scale organization of topography, soil moisture, soil temperature, and vegetation on modeling surface microwave radiation emission. IEEE Transactions on Geoscience \& Remote Sensing, 47, 2557, 2009.

5. GARY C.H., PATRICK J.S., LAJPAT R.A., THOMAS J.J. Assimilation of surface soil moisture to estimate profile soil water content. Journal of Hydrology, 279, 1, 2003.

6. JACKSON T.J. Measuring surface soil moisture using passive microwave remote sensing. Hydrological Processes, 7, 139, 1993.

7. KOSTOV K.G., JACKSON T.J. Estimating profile soil moisture from surface layer measurements: A review. Proc. SPIE, 1941, 125, 1993.

8. BéHAEGEL M., SAILHAC P., MARQUIS G. On the use of surface and ground temperature data to recover soil water content information. Journal of Applied Geophysics, 62, 234, 2007.

9. MERLIN O., AL B.A., WALKER J.P. An improved algorithm for disaggregating microwave-derived soil moisture based on red, nearinfrared and thermal-infrared data. Remote Sensing of Environment, 114, 2305, 2010.

10. PAN M., SAHOO A.K., WOOD E.F. Improving soil moisture retrievals from a physically based radiative transfer model. Remote Sensing of Environment, 140, 130, 2014.

11. TEMIMI M., LECONTE R., CHAOUCH N., SUKUMAL P., KHANBIVARDI R., BRISSETTE F. A combination of remote sensing data and topographic attributes for the spatial and temporal monitoring of soil wetness. Journal of Hydrology, 388, 28, 2010.

12. PARINUSSA R.M., HOLMES T.R.H., de JEU R.A.M. Soil moisture retrievals from the WindSat spaceborne polarimetric microwave radiometer. IEEE Transactions on Geoscience and Remote Sensing, 50, 2683, 2012.

13. SUNGWOOK H., INCHUL S. A physically-based inversion algorithm for retrieving soil moisture in passive microwave remote sensing. Journal of Hydrology 405, 24, 2011.

14. ROTH K., SCHULIN R., FLUEHLER H., ATTINGER W. Calibration of TDR for water content measurement using a composite dielectric approach. Water Resources Research, 26, 2267, 1990 .

15. RAHIMZADEH-BAJGIRAN P., BERG A.A., CHAMPAGNE C. Estimation of soil moisture using optical/thermal infrared remote sensing in the Canadian Prairies. ISPRS Journal of Photogrammetry and Remote Sensing, 83, 94, 2013.

16. QU W., BOGENA H.R., HUISMAN J.A., VEREECKEN $\mathrm{H}$. Calibration of a novel low-cost soil water content sensor based on a ring oscillator. Vadose Zone J. 12, 1, 2013.

17. RAHIMZADEH-BAJGIRAN P., OMASA K., SHIMIZU Y. Comparative evaluation of the Vegetation Dryness Index (VDI), the Temperature Vegetation Dryness Index (TVDI) and the improved TVDI (iTVDI) for water stress detection in semi-arid regions of Iran. ISPRS Journal of Photogrammetry and Remote Sensing, 68, 1, 2012.

18. ROSENBAUM U., BOGENA H.R., HERBST M., HUISMAN J.A., PETERSON T.J., WEUTHEN A., WESTERN A.W. VEREECKEN H. Seasonal and event dynamics of spatial soil moisture patterns at the small catchment scale. Water Resources Research, 48, 3472, 2012.

19. RÜDIGER C., WALKER J.P., KERR Y., KIM E.J., HACKER J., GURNEY R., BARRETT D, MARSHALL J. Toward Vicarious Calibration of Microwave RemoteSensing Satellites in Arid Environments. IEEE Transactions on Geoscience and Remote Sensing, 52, 1749, 2014.

20. SCHWALM C.R., EK A.R. A process-based model of forest ecosystems driven by meteorology. Ecological Modelling, 179, 317, 2004.

21. HASAN S., MONTZKA C., RüDIGER C., ALI M., BOGENA H.R., VEREECKEN H. Soil moisture retrieval from airborne L-band passive microwave using high resolution multispectral data. ISPRS Journal of Photogrammetry and Remote Sensing, 91, 59, 2014.

22. WAN Z., WANG P., LI X. Land Surface Temperature and Normalized Difference Vegetation Index Products for Monitoring Drought in the Southern Great Plains. International Journal of Remote Sensing, 25, 61, 2005.

23. JU W.M., GAO P., WANG J. Combining an ecological model with remote sensing and GIS techniques tomonitor soil water content of croplands with a monsoon climate. Agricultural Water Management, 97, 1221, 2010. 